Claudia Jones

Communist Party of Great Britain, United Kingdom

\title{
Um fim à negligência em relação aos problemas da mulher negra!
}

Resumo: O artigo é a tradução de um ensaio publicado originalmente em 1949, pela intelectual e ativista negra Claudia Jones na revista Political Affairs. No ensaio, Jones demonstra as origens e as múltipmas dimensões da dinâmica do sistema de opressão a que eram submetidas mulheres negras e critica a inabilidade dos comunistas estadunidenses em mobilizá-las. Ao argumentar que as mulheres negras compunham a fração superexplorada da classe trabalhadora, a autora as posiciona como parecela central da militância internacional contra o fascismo e o imperialismo.

Palavras-chave: Claudia Jones; comunismo; mulheres negras; feminismo negro

\section{Apresentação}

Claudia Jones foi uma intelectual e ativista negra com trajetória singular na tradição radical negra, especialmente por seu engajamento no campo político da esquerda, associado a uma postura notadamente feminista, antirracista e anti-imperialista. Até a publicação recente de Left of Karl Marx: The Life of Black Communist Claudia Jones (2008), da autora Carole Boyce Davies, a vida e o pensamento de Claudia Jones haviam recebido pequena atenção acadêmica. Mesmo com o excelente trabalho de Davies e de outros subsequentes, Jones segue recebendo pouca atenção no conjunto de intelectuais que são identificadas como referência na escola de pensamento feminista negro e da tradição intelectual radical negra.

Claudia Jones nasceu como Claudia Vera Cumberbatch, em 1915, na cidade de Porto de Espanha, em Trinidad. Em 1924, migrou, com seus pais e irmãs, Sylvia, Meta, Irene e Lindsay, para o Harlem, em Nova lorque. No início dos anos 1930, a jovem Jones se envolveu na mobilização nacional pela libertação dos "Scottsboro Boys", nove jovens negros falsamente acusados de violentar sexualmente uma mulher branca no Alabama, em 1931. Pouco tempo depois, ela ingressou no Partido Comunista dos Estados Unidos e passou a integrar a Liga Comunista da Juventude (Communist Youth League), tornando-se uma das lideranças jovens mais ativas do partido.

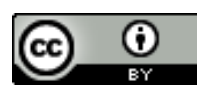

Esta obra está sob licença Creative Commons. 
Nos primeiros anos de militância, Jones contribuiu como uma das editoras no The Daily Worker e de outros jornais da imprensa comunista estadunidense. Outra atividade que marcou a trajetória de Jones no partido comunista foi o recrutamento de mulheres negras da classe trabalhadora para as fileiras do partido, o que foi a causa principal para sua prisão, em 1948, que a submeteu a um processo de deportação. Após cumprir uma pena de um ano de encarceramento, em 1955, que agravou um problema cardíaco, Jones resolveu se mudar para a Inglaterra e encerrar a longa batalha judicial que travava para permanecer nos Estados Unidos. Em Londres, ela continuou sua militância comunista, ingressando no Partido Comunista da Grã-Bretanha, além de participar do Congresso Trabalhista Caribenho e contribuir para a fundação da Associação de Trabalhadores e Estudantes das Índias Ocidentais (West Indian Workers and Students' Association). A associação foi uma organização central na luta contra o racismo e restrições imigratórias a que a comunidade caribenha era submetida na capital inglesa, e, também, contra o apartheid, na África do Sul.

Claudia Jones tornou-se uma das principais porta-vozes da comunidade caribenha na Inglaterra. Em 1958, ela fundou e passou a atuar como editora no jornal West Indian Gazette e Afro-Asian Caribbean News, voltado para a mobilização dos caribenhos e, também, para a promoção de ideias comunistas. Em 1959, foi uma articulista central na organização do anual carnaval caribenho em Londres, que é realizado até os dias de hoje.

Jones permaneceu em Londres até sua morte, em 1964, quando foi acometida por um ataque cardíaco, após anos sofrendo com problemas de coração. Suas cinzas foram enterradas em um túmulo à esquerda de Karl Marx, no Cemitério de Highgate, em Londres. A mensagem gravada na lápide de Claudia Jones revela que a escolha do lugar para guardar suas cinzas não foi coincidência: "Corajosa lutadora contra o racismo e o imperialismo, que dedicou sua vida para o progresso do socialismo e a liberação do povo negro".

A tradução deste ensaio clássico, publicado em 1949, faz parte de um esforço em ampliar o público leitor de Claudia Jones no Brasil e em outros países de língua portuguesa. Considerando, especificamente, o público brasileiro, o trabalho da autora apresenta uma oportunidade singular de explorar uma perspectiva que enfatiza as condições sociais e políticas das mulheres negras nos Estados Unidos. O texto é uma denúncia da inabilidade do Partido Comunista em mobilizar mulheres negras, em sua maioria trabalhando como empregadas domésticas, na luta por direitos do trabalho. A incapacidade comunista em atrair mulheres negras para suas fileiras persistia mesmo em face da realidade que as posicionava como a classe mais explorada, ou como Jones denominou a fração superexplorada da classe trabalhadora nos Estados Unidos. Um dos argumentos centrais de Jones, no ensaio, é que mulheres negras estavam habituadas a desenvolver uma militância em suas comunidades, a qual reforçaria os esforços comunistas no país se fossem introduzidas na prática política do partido, mas racismo e machismo impediam que o valor da mobilização dessas mulheres fosse reconhecido.

Mesmo próximo de completar 70 anos, o ensaio de Claudia Jones ainda é relevante, atualmente, tanto para o Brasil quanto para os Estados Unidos. Mulheres negras ainda hoje se encontram majoritariamente entre os superexplorados, mas a mobilização dessas trabalhadoras continua a ser um desafio. A esquerda no Brasil está sendo forçada a enfrentar os ataques ao projeto social democrata, implementado durante a última década. Nesse contexto, a leitura do texto pode ser feita como uma inspiração para a elaboração de uma crítica feminista negra de esquerda para o Partido dos Trabalhadores e outros partidos que se identificam com essa ideologia política. Enquanto ativistas radicais continuarem a se organizar ao longo das Américas, este ensaio irá nos encorajar a perguntar: qual o lugar das mulheres negras nos esforços para transformação radical das condições políticas e sociais da população mais pobre, de mulheres e negros? Esse ensaio é apenas um de muitos documentos que Claudia Jones deixou para nos ajudar a refletir sobre essa questão. 


\section{Um fim à negligência em relação aos problemas da mulher negra!'}

Uma característica marcante do atual estágio do movimento de libertação negra (Black ${ }^{2}$ Liberation Movement) é a crescente participação de mulheres negras, em todos os aspectos da luta por paz, direitos civis e estabilidade econômica. Um fato sintomático dessa nova militância é que mulheres negras têm se tornado símbolo de muitas lutas contemporâneas do povo negro. Esse aumento de militância entre mulheres negras tem um profundo significado, tanto para o movimento de libertação negra quanto para a emergente coalizão antifascista e anti-imperialista.

A correta compreensão dessa militância, bem como o aprofundamento e ampliação do papel da mulher negra na luta por paz e pelos interesses das mulheres trabalhadoras, e do povo negro, passa, primeiramente, pela superação da profunda negligência com que vêm sendo tratados os problemas específicos das mulheres negras. Essa negligência tem, por muito tempo, permeado as fileiras dos movimentos dos trabalhadores em geral, dos movimentos progressistas de esquerda e, também, do Partido Comunista. ${ }^{3}$ Uma cobrança mais séria sobre essa falha dos progressistas, especialmente dos marxistas-leninistas, é vitalmente necessária, se quisermos colaborar para acelerar a mudança e integrar mulheres negras nos movimentos trabalhistas e progressistas e no nosso Partido. A burguesia está temerosa da militância da mulher negra, e por um bom motivo. Os capitalistas sabem, melhor que muitos progressistas, que uma vez que mulheres negras entrem em ação, a militância de todo o povo negro, assim como da coalizão anti-imperialista, será bastante reforçada.

Historicamente, a mulher negra tem sido a guardiã, a protetora da família negra. Desde os dias de escravização até o presente, a ela é reservada a responsabilidade de cuidar das necessidades da família, de blindá-la militantemente contra os golpes dos insultos do Jim-Crow, ${ }^{4}$ de educar crianças em uma atmosfera cercada pelo terror dos linchamentos, segregação e brutalidade policial, e de lutar por escolarização para as crianças. A intensificação da opressão contra o povo negro, que tem sido a marca da ofensiva reacionária do pós-guerra, só pode conduzir para uma aceleração da militância da mulher negra. Como mãe, como negra, como trabalhadora, a mulher negra luta contra o extermínio da família negra, contra a existência de gueto criada pelo Jim Crow que destrói a saúde, a moral e a própria vida de milhões de suas irmãs, seus irmãos e crianças negras.

Visto sob esta luz, não é um acidente que a burguesia americana tenha intensificado a opressão, não somente contra o povo negro em geral, mas contra a mulher negra em particular. Nada expõe tanto a pulsão fascista na nação (americana), que a atitude indiferente que a burguesia demonstra e cultiva em relação às mulheres negras. O vanglorio alardeado pelos ideólogos das Grandes Corporações - de que mulheres americanas possuem "o maior nível de igualdade" no mundo - fica exposto em toda sua hipocrisia

\footnotetext{
'A versão original foi publicada na Political Affairs. Atualmente está publicado em People's World (http:// www.peoplesworld.org) sob Licença Creative Commons 3.0, United States.

${ }^{2}$ Nota da tradutora: No texto original, Claudia Jones usa o termo "Negro" em inglês e, não, a palavra "Black", que, intencionalmente, utilizamos aqui. Derivado do espanhol e português e, depois, usado para caracterizar os povos originados da África, o termo "Negro" era aceitável naquele contexto histórico. Hoje, seu uso seria considerado ofensivo e nunca usado em documentos públicos.

${ }^{3}$ Nota da tradutora: Refere-se ao Partido Comunista dos Estados Unidos (Communist Party USA), fundado em 1919 e ativo hoje.

${ }^{4}$ Nota da tradutora: As leis de Jim Crow foram leis que legalizaram a segregação racial no sul dos Estados Unidos, formuladas pelos estados e implementadas durante os anos seguintes à abolição da escravidão, que vigoraram até 1965. No norte do país, a segregação racial foi de facto - na qual práticas de segregação racial na moradia, educação, espaços públicos, e emprego não foram reguladas por um corpo de leis da Jim Crow, mas por costumes discriminatórios.
} 
quando se vê que, em muitas partes do mundo, particularmente na União Soviética, nas Novas Democracias e em outrora oprimidas regiões da China, mulheres estão obtendo novos níveis de igualdade. Mas, acima de tudo, a autovanglória de Wall Street não chega às margens do assunto ${ }^{5}$ quando se trata de mulheres negras da classe trabalhadora. Não igualdade, mas degradação e superexploração: essa é a realidade das condições das mulheres negras!

Consideremos a hipocrisia da administração Truman, que se gaba de "exportar democracia para todo o mundo", enquanto o estado de Geórgia mantém uma mulher negra viúva e mãe de doze crianças trancada a sete chaves. Seu crime? Ela defendeu sua vida e dignidade - com o auxílio de dois de seus filhos - dos ataques de um "supremacista branco". Ou, enquanto observamos o completo silêncio que o Departamento de Justiça dispensou à senhora Amy Mallard, mulher negra, professora, viúva depois que seu marido foi linchado na Geórgia, por ter comprado um novo Cadillac e se tornado, na opinião de "supremacistas brancos", "arrogante demais". Podemos contrastar esses eventos com as lágrimas de crocodilo derramadas em nome do Cardeal Mindszenty, pela delegação dos Estados Unidos para as Nações Unidas, ${ }^{6}$ que colaborou com os inimigos da República do Povo Húngaro e buscou impedir o avanço da marcha para uma plena democracia para os previamente oprimidos trabalhadores e camponeses húngaros. Recentemente, o presidente Truman falou com solicitude, em um pronunciamento do Dias das Mães, sobre a expressão de "nosso amor e reverência" por todas as mães de nossa terra. Esse suposto "amor e reverência" pelas mães da nação, de forma alguma, inclui mães negras que - a exemplo de Rosa Lee Ingram, Amy Mallard, das esposas e mães dos Seis de Trenton, ${ }^{7}$ ou de outras incontáveis vítimas - ousam lutar contra a violência da lei do linchamento e da "supremacia branca".

\section{Dificuldades econômicas}

Muito ao contrário [do amor e reverência professados por Truman], mulheres negras enquanto classe trabalhadora, como negras, e mulheres - são o estrato mais oprimido de toda população.

Em 1940, duas de cada cinco mulheres negras, em contraste com duas em cada oito mulheres brancas, trabalhavam para viver. Em virtude de seu status como maioria da população negra, mulheres negras não somente constituem a maior porcentagem de chefes de família, mas, também, são a principal fonte de renda da família negra. A larga proporção de mulheres negras no mercado de trabalho é, primariamente, resultado dos baixos rendimentos dos homens negros [o que as obriga a trabalhar para complementar a renda da família]. Essa desproporção também tem suas raízes no tratamento dado e na posição das mulheres negras ao longo dos séculos.

\footnotetext{
${ }^{5}$ Nota da tradutora: Jones usa a expressão "stops at the water's edge", que tem uma tradução literal de "para na borda da água". Usada primeiramente pelo Presidente Harry S. Truman (1945-1953), esta expressão, na política estadunidense, significa que o país tem que apresentar uma frente unida para o mundo, mesmo embora com divergências internas, para assim parecer um grande e forte país.

${ }^{6}$ Nota da tradutora: Em 1949, o cardeal József Mindszenty foi condenado à prisão na República Popular da Hungria, governada pelo Partido Comunista Húngaro. O julgamento do cardeal foi alvo de duras críticas da Organização das Nações Unidas, cujas assembleias contaram com intensa participação do governo dos Estados Unidos.

${ }^{7}$ Nota da tradutora: Os Trenton Six (Seis de Trenton) foram um grupo de seis homens negros julgados pela morte de um comerciante branco. Condenados à morte por um júri branco, o episódio virou um caso simbólico e mobilizou muitos ativistas contra as práticas legais injustas, especialmente a falta de evidência forense que colocasse os homens no lugar em que aconteceu o crime. O caso atraiu muita atenção no país e o apoio de grandes organizações na luta por direitos civis.
} 
Após a emancipação, e até os dias atuais, a larga porcentagem de mulheres negras - tanto as casadas quanto as solteiras - foi forçada a trabalhar para viver. Mas, apesar da transição dos empregos de áreas rurais para urbanas, mulheres negras ainda estão, em geral, confinadas a empregos de baixa remuneração. O Handbook of Facts for Women Workers [Manual da realidade das mulheres trabalhadoras], do Women's Bureau, U.S. Department of Labor [Secretaria de Mulheres do Ministério do Trabalho] (1948, Boletim 225), revela que mulheres brancas têm, em média, mais que o dobro dos rendimentos de mulheres não brancas; e mulheres não brancas (majoritariamente mulheres negras) recebem menos que $\$ 500$ (quinhentos dólares) por ano! Na região rural do sul dos Estados Unidos, os rendimentos femininos são ainda mais baixos. Nos três maiores centros industriais do Norte dos Estados Unidos, a média de renda de famílias brancas $(\$ 1,720)$ é quase 60 por cento maior que de famílias negras $(\$ 1,095)$. Dessa forma, a superexploração da mulher negra é revelada não somente na medida em que ela recebe, como mulher, menos pelo mesmo trabalho desempenhado por homens, mas, também, na medida em que recebem menos que a metade do pagamento de mulheres brancas. Não é de admirar, então, que, em comunidades negras, as condições de vida - baixos salários, aluguéis caros, preços altos etc. - tenham se tornado uma virtual cortina de ferro, limitando as possibilidades de futuro de crianças negras e debilitando sua saúde e espírito! Não é de admirar que a taxa de mortalidade materna para mulheres negras seja o triplo que para mulheres brancas! Não é de admirar que uma entre dez crianças negras nascidas nos Estados Unidos não chegue à idade adulta.

A baixa escala de rendimentos que a mulher negra recebe está diretamente relacionada à sua quase completa exclusão da maioria das áreas de trabalho, exceto as mais servis e mal pagas, nomeadamente o trabalho doméstico. Os seguintes dados, do relatório Negro Women War Workers [Mulheres Negras Trabalhadoras na Guerra], de 1945, do Women's Bureau, U.S. Department of Labor, Bulletin 205 [Secretaria de Mulheres do Ministério do Trabalho, Boletim 205] são reveladores: do total de 7,5 milhões de mulheres negras nos Estados Unidos, mais de um milhão trabalha no serviço doméstico. A esmagadora maioria, cerca de 918 mil, das mulheres negras trabalhadoras está empregada em casas particulares; e cerca de 98 mil trabalham como cozinheiras, garçonetes, e em serviços semelhantes, em outros tipos de estabelecimentos. O restante de 60 mil trabalhadoras da área de serviços está empregada em diversas ocupações (esteticistas, faxineiras em pensões e hospedarias, diaristas, zeladoras, assistentes de enfermagem, caseiras, recepcionistas e ascensoristas).

Em seguida, a área com maior número de mulheres negras empregadas é o trabalho agrícola. Em 1940, cerca de 240 mil eram trabalhadoras agrícolas, das quais, quase 128 mil trabalhavam em suas próprias famílias e não eram remuneradas.

Mulheres negras trabalhadoras na indústria contavam mais que 96 mil, das quais 36 mil trabalhavam na produção. Os principais setores eram: 11.300, vestuário e outros produtos têxteis; 11 mil, produção de tabaco; e 5.600, produtos alimentícios e afins.

As trabalhadoras do setor administrativo e afins somavam somente 13 mil. Naquela ocasião, havia apenas 8.300 mulheres negras trabalhando no setor público.

O restante das mulheres negras que trabalhava para viver estava distribuído entre os seguintes setores: professoras, 50 mil; enfermeiras e estudantes de enfermagem, 6.700; assistentes sociais, 1.700; dentistas, farmacistas e veterinárias, 120; médicas e cirurgiãs, 129; atrizes, 200; autoras, editoras e repórteres, 100; advogadas e juízas, 39; bibliotecárias, 400; e outras categorias, ilustrando, da mesma forma, a exclusão em larga escala de mulheres negras das profissões.

Durante a guerra contra as potências do Eixo, mulheres negras tiveram, pela primeira vez na história, a oportunidade de utilizar suas habilidades e talentos em ocupações diferentes do serviço doméstico, tornando-se pioneiras em muitas áreas. Desde o final da 
guerra, entretanto, essa situação deu lugar a um crescente desemprego, a uma demissão em massa de mulheres negras, especialmente na indústria de base.

Esse processo tem se intensificado com o desenvolvimento da crise econômica. Atualmente, um grande número de mulheres negras está sendo forçada a reingressar no trabalho doméstico. No estado de Nova lorque, por exemplo, essa tendência foi confirmada de forma oficial recentemente, quando Edward Corsi, encarregado do Ministério do Trabalho, revelou que, pela primeira vez desde a guerra, serviço doméstico pode ser contratado facilmente. Corsi, em efeito, admitiu que mulheres negras não estão desistindo de seus empregos voluntariamente, mas que estão sendo sistematicamente colocadas para fora do setor da indústria. O desemprego, que sempre atingiu a mulher negra primeiro e mais duramente, somado ao alto custo de vida, é o que compele mulheres negras a reingressar no serviço doméstico atualmente. Em adição a essa tendência, existe uma campanha ideológica para tornar o emprego doméstico palatável. Diariamente, anúncios de jornais baseiam seus argumentos na alegação que a maioria dos trabalhadores do serviço doméstico que procura serviço por via do U.S.E.S. [Agência de Empregos dos Estados Unidos] "prefere esse tipo de trabalho do que trabalhar na indústria", propagandeiam as "virtudes" do trabalho doméstico, especialmente as vagas que exigem que se durma no emprego.

Um fator intimamente associado à questão das oportunidades de trabalho para a mulher negra é a especial opressão que ela sofre como negra, como mulher e como trabalhadora. A mulher negra é vítima do estereótipo machista branco a respeito do lugar que deve ocupar [na sociedade]. No cinema, no rádio e na imprensa, a mulher negra não é representada em seu verdadeiro papel: como chefe, mãe e protetora da família. Mas somente como uma "mãe preta" tradicional, que coloca o cuidado das crianças das famílias dos outros acima de sua própria. O estereótipo tradicional da mãe negra escrava, que, até hoje, aparece em propagandas, deve ser combatido e rejeitado como um aparato do imperialismo para perpetuar a ideologia branca machista de que as mulheres negras são "atrasadas", "inferiores" e "escravas naturais" de outros.

\section{Aspectos históricos}

Efetivamente, a história da mulher negra mostra que, durante a escravidão, a mãe negra ocupava uma posição estratégica, desempenhando um papel central em seu agrupamento familiar. Isso devido, primeiramente, a dois fatores: as condições da escravidão, em que casamentos legais não existiam, e o status social do negro, que era derivado da mãe e não do pai; e o fato de que a maioria da população negra, trazida para essas terras a bordo dos navios negreiros, era proveniente da África Ocidental, onde, com base na participação ativa no controle de propriedade, a posição da mulher na família era relativamente superior se comparada com mulheres europeias.

Antigos historiadores, estudiosos do tráfico negreiro, relataram o depoimento de viajantes que indicavam que o amor da mãe africana por seus filhos era inigualável com o que presenciaram em qualquer outra parte do mundo. Existem numerosas estórias atestando para o sacrifício pessoal de mães do leste africano que se ofereciam como escravas para os mercadores com intuito de salvar seus filhos, assim como a recusa de comida de mulheres Hotentotes em períodos de fome até que seus filhos fossem alimentados.

Não é possível, nos limites deste artigo, descrever os terríveis sofrimentos e degradação a que mães negras e mulheres negras eram comumente submetidas durante o período de escravidão. Sujeitas ao estupro legalizado dos senhores de escravos, confinadas em mercados de escravos, forçadas a andar de oito a quatorze horas por dia com cargas nas costas e a realizar tarefas extenuantes, inclusive durante a gravidez, mulheres negras 
desenvolveram um ódio ardente pela escravidão, ficando encarregadas de uma grande parcela da responsabilidade de defender e sustentar a família negra.

A mãe negra tinha autoridade no barracão de escravos, e, mesmo apesar da interferência do senhor de escravos ou dos capatazes, sua vontade era respeitada, no que dizia respeito a uniões amorosas e questões familiares. Durante e depois da escravidão, mulheres negras tiveram que se sustentar e a seus filhos, desempenhando um importante papel na vida econômica e social de suas comunidades. Mulheres negras tornaram-se experientes em autoconfiança, coragem e ações abnegadas. ${ }^{8}$

Existe material documental de grande importância, demonstrando que, após a emancipação, a vida da família negra e a consciência política e social de homens e mulheres negras foram submetidas a consideráveis mudanças. Um escravo liberto notou, durante a Guerra Civil [nos Estados Unidos], que muitos homens estavam muito ciosos de sua recém adquirida autoridade nas relações familiares e insistiam que fossem reconhecidos em sua superioridade sobre mulheres. Após a Guerra Civil, o sistema de moradia coletiva dos escravos [senzala] foi desmantelado, substituído pelo arrendamento, com casas dispersas ao longo das fazendas, de modo que cada família pudesse conviver de forma independente. O novo arranjo econômico, a mudança na forma de produção, colocou o homem negro em uma posição de autoridade na família. A aquisição de propriedades rurais também ajudou a fortalecer a autoridade masculina.

Assim, um ex-escravo que começou a vida como um homem livre em uma pequena roça, com sua esposa trabalhando como lavadeira, e, que, mais tarde, arrendou mais terras e contratou dois empregados, recorda do orgulho que sentiu em função de seu novo status: "Em meu humilde palácio, em uma colina na floresta sob a sombra das imponentes pinheiros e carvalhos resistentes, eu me sentia um rei cujo comando supremo era 'lei e evangelho' para os meus subordinados".

Podem-se perceber, aqui, duas forças motrizes em operação. No que se refere à sua mulher e filhos, o homem negro passou a assumir autoridade econômica sobre a família; mas também passou a poder lutar contra o estupro de mulheres do seu grupo, interferência que outrora lhe era negada.

A fundação de igrejas negras, que, de início, estavam sob o domínio de homens, também contribuiu para confirmar a autoridade masculina na família. Confirmações do domínio masculino foram encontradas na Bíblia, que, para muitos, era a autoridade superior em tais assuntos.

Por via desses e de outros métodos, a subordinação da mulher negra se expandiu. Em certos casos, ao invés da emancipação legal de sua esposa e filhos, maridos permitiram que eles continuassem na condição de escravos. Em outros casos, a legislação do Estado proibia que escravos emancipados permanecessem no mesmo estado. Por consequência, a única forma para que muitas esposas negras e seus filhos continuassem a viver no mesmo local era ser "escravizados" por seus familiares.

Em alguns casos, mulheres negras se recusaram a tornar-se sujeitas à autoridade masculina. Em desafio às decisões de seus maridos de viver em locais providos por seus exsenhores, muitas mulheres negras se mudaram com seus filhos.

\section{Mulheres negras em organizações de massa}

Esse breve panorama de alguns dos aspectos da história da mulher negra, vistos à luz do fato de que uma grande proporção de mulheres negras é obrigada, atualmente, a

\footnotetext{
${ }^{8}$ Nota original: Atualmente, em áreas rurais do sul [dos estados Unidos], especialmente nos remanescentes das velhas plantations [fazendas], podem-se encontrar famílias em que avós lideram suas filhas, seus filhos e netos com uma autoridade matriarcal.
} 
ganhar todo ou parte do pão da família, nos ajuda a entender o motivo de desempenharem um papel muito ativo na vida econômica, social e política da comunidade negra. Aproximadamente 2 milhões e 500 mil mulheres negras estão organizadas em clubes e organizações sociais políticas ou irmandades. As organizações mais proeminentes são: National Association of Negro Women [Associação Nacional de Mulheres Negras]; National Council of Negro Women [Conselho Nacional de Mulheres Negras]; National Federation of Women's Clubs [Federação Nacional de Clubes de Mulheres]; Women's Division of Elks' Civil Liberties Committee [Divisão Feminina do Comitê de Liberdades Civis da Fraternidade Elks]; National Association of Colored Beauticians [Associação Nacional de Esteticistas Negras]; National Negro Business Women's League [Liga Nacional de Comerciantes Negras]; e National Association of Colored Graduate Nurses [Associação Nacional de Enfermeiras Negras]. Dessas organizações, a Associação Nacional de Mulheres Negras, com 75 mil integrantes, é a maior associação com filiação. Existem numerosas irmandades, comitês de mulheres religiosas de várias denominações, assim como organização de mulheres de origem caribenha. Em algumas regiões, filiais da N.A.A.C.P. [Associação Nacional para o Avanço de Pessoas Negras] têm seções de mulheres, e, recentemente, a National Urban League [Liga Urbana Nacional] estabeleceu uma seção feminina pela primeira vez na história.

Mulheres negras são a verdadeira força ativa - organizadores e trabalhadoras - em todas as instituições e organização do povo negro. Essas organizações desempenham um papel multifacetado, cuidando de questões relacionadas com a vida econômica, política e social do povo negro, especialmente da família negra. Em muitas dessas organizações há uma profunda preocupação com problemas da juventude negra, por isso oferecem e administram bolsas de estudos, dão assistência para escolas e outras instituições, e oferecem serviços comunitários. A luta por educação superior, para eliminar o Jim Crow em instituições de ensino superior, foi simbolizada ano passado, pela brilhante estudante negra, Ada Lois Sipuel Fisher, de Oklahoma. As atitudes desdenhosas, que são, às vezes, expressas - de que organizações de mulheres negras se dedicam apenas à caridade - devem ser expostas como uma derivação do machismo, ainda que sutil. Enquanto o mesmo pode ser dito de muitas organizações de mulheres brancas, essas atitudes não reconhecem o caráter especial do papel de organizações de mulheres negras. Esse tipo de abordagem falha em reconhecer a função específica que as mulheres negras desempenham nessas organizações, que, para além de suas funções particulares, visam proporcionar a assistência social negada à juventude negra, como resultado do sistema de linchamento do Jim Crow nos Estados Unidos.

\section{A mulher negra trabalhadora}

A reduzida participação de mulheres negras em círculos progressistas e sindicais é um tanto quanto surpreendente. Em sindicato após sindicato, mesmo naqueles com forte concentração de trabalhadoras negras, poucas mulheres negras se encontram em posições de liderança. As únicas exceções são os sindicatos de trabalhadores das áreas alimentícias e produção de tabaco: o Sindicato Unificado dos Trabalhadores.

Mas, por que a participação de mulheres negras nesses sindicatos deve ser exceção? Mulheres negras estão entre as mais combativas militantes sindicais. As greves de arrendatários de terra dos anos [19]30 foram lideradas por mulheres negras. Sujeitas ao terror dos proprietários de terras e de supremacistas brancos, elas travaram magníficas batalhas, em companhia de homens negros e brancos progressistas, nessa tradicional luta do Partido Comunista. Mulheres negras tiveram uma participação magnífica nos "pré-ClO" dias, nas greves e outras lutas, tanto como trabalhadoras quanto como esposas de trabalhadores, para ter reconhecido o direito sindical para os trabalhadores de indústrias, como a automobilística, de embalagens, 
siderúrgica etc. Recentemente, a militância de mulheres negras sindicalizadas tem se mostrado nas greves de trabalhadores da indústria de utensílios domésticos, e, mais ainda, na greve dos trabalhadores da indústria do tabaco - em que líderes como Moranda Smith e Velma Hopkins emergiram como proeminentes sindicalistas. A luta dos trabalhadores da indústria do tabaco, liderada por mulheres negras, fundiu-se, posteriormente, com a ação política de negros e brancos que levou à eleição do primeiro negro no sul [dos Estados Unidos] (em Winston-Salem, Carolina do Norte), desde os dias da Reconstrução. ${ }^{9}$

É responsabilidade dos sindicalistas progressistas compreender que, na luta por direitos iguais para trabalhadores negros, é necessário ter uma abordagem especial dedicada às mulheres negras trabalhadoras, que excedem em muito a proporção de outras mulheres trabalhadoras e estão, em maioria, na chefia de suas famílias. A luta para reter a mulher negra na indústria e para melhorar suas condições de trabalho é uma via importante de luta pelos interesses básicos e específicos da mulher negra trabalhadora. Não reconhecer essa especificidade é não observar os aspectos particulares dos efeitos da crescente crise econômica que está penalizando mulheres negras, em especial as trabalhadoras, com mais gravidade.

\section{A trabalhadora doméstica}

Uma das mais grosseiras manifestações da negligência sindical com os problemas da mulher negra trabalhadora tem sido a incapacidade, não somente em lutar contra o fato de ser relgada ao trabalho doméstico e outros similares trabalhos servis, mas de organizar a trabalhadora doméstica. É uma hipocrisia dos sindicalistas progressistas falar em organizar os desorganizados sem atentar para a grave situação da trabalhadora doméstica, que, desprotegida do direito sindical, fica, também, excluída de toda a legislação social e trabalhista. Somente cerca de uma em dez trabalhadoras negras está assegurada pela atual legislação do salário mínimo, embora um quarto dessas trabalhadoras se encontre em estados que possuem legislação regulando o salário mínimo. Todos os argumentos elaborados até o momento sobre as dificuldades de organizar as trabalhadoras domésticas - como a natureza "casual" de seu emprego, as dificuldades de organizar diaristas, o problema em organizar pessoas que trabalham em casas particulares etc. - devem ser superados imediatamente. Há um perigo de que forças sociais democratas possam entrar nesse campo para fazer seu trabalho de espalhar desunião e demagogia, a menos que progressistas ajam rapidamente.

A sina da trabalhadora doméstica é de uma miséria insuportável. Normalmente, não há uma definição de suas tarefas nas casas onde trabalha. Trabalhadoras domésticas podem ter incluídas em seu serviço, além de limpar e esfregar, tarefas como lavar vidraças, cuidar de crianças, lavar, cozinhar etc., e tudo isso a baixíssimos salários. A trabalhadora doméstica negra pode sofrer humilhação extra, em algumas áreas, de ter de procurar trabalho em virtuais "mercados de escravos", em ruas onde se fazem lances, de um "slave block" pelos trabalhadores mais resistentes. Muitas trabalhadoras domésticas, no retorno às suas próprias casas, são forçadas a uma segunda jornada de trabalho doméstico para manter sua própria família em pé.

Quem não ficou com raiva quando foi revelado que, na Califórnia, no odioso caso de Dora Jones, uma doméstica negra foi escravizada por mais de 40 anos em plena

${ }^{9}$ Nota da tradutora: O termo Reconstrução refere-se ao período de 1863 a 1877, imediatamente posterior à Guerra Civil nos Estados Unidos e à abolição da escravidão, marcado por esforços para reestruturação política e econômica do país, que teve um impacto radical no acesso de negros a educação e a voz política. O projeto falha, principalmente, por causa do aumento de grupos de supremacistas brancos como a Klu Klux Klan.

Estudos Feministas, Florianópolis, 25(3): 1001-1016, setembro-dezembro/2017 1009 
América "civilizada"? O "empregador", nesse caso, recebeu uma sentença mínima de poucos anos e se queixou que a sentença foi para "um período tão longo". Mas Dora Jones, trabalhadora doméstica negra, não deveria ser paga pelos mais de 40 anos de sua vida sob tais condições de exploração e degradação? E muitos outros casos, que compartilham em vários níveis da condição de Dora Jones, são ainda tolerados pelos progressistas!

Recentemente, na legislação do estado de Nova lorque, propostas foram feitas para que fossem colhidas impressões digitais de trabalhadoras domésticas. Esse projeto de lei (Martinez Bill) não chegou a ver a luz do dia, porque os reacionários se concentraram em outras medidas legislativas repressivas. Aqui, porém, nós vemos claramente a marca do sistema do "passe" africano do imperialismo britânico (e do Reich alemão em relação ao povo judeu!) sendo proposto com relação a trabalhadoras domésticas.

É uma incumbência dos sindicatos auxiliar o sindicato das trabalhadoras domésticas de toda forma possível para que consigam realizar a tarefa de organizar as trabalhadoras domésticas exploradas, a maioria das quais são mulheres negras. Simultaneamente, uma luta no legislativo para inclusão de trabalhadoras domésticas nos benefícios da lei de seguridade social é vitalmente urgente e necessária. Também neste momento, questões sobre "problemas administrativos" na aplicação da lei para trabalhadoras domésticas devem ser contestadas e soluções devem ser encontradas.

O contínuo fato de relegar a mulher ao trabalho doméstico tem contribuído para perpetuar e intensificar o chauvinismo contra todas as mulheres negras. Apesar do fato de que mulheres negras podem ser avós ou mães, o uso do termo machista "moça" (girl) para se referir a mulheres negras adultas é uma expressão comum. O próprio relacionamento econômico de mulheres negras com mulheres brancas, que perpetua relações do tipo "senhora-criada", alimenta atitudes machistas e gera uma obrigatoriedade para mulheres brancas progressistas, em especial as comunistas, lutarem conscientemente contra toda manifestação de chauvinismo branco, escancarado ou sutil.

O chauvinismo por parte de mulheres progressistas brancas é frequentemente expresso na sua incapacidade de ter estreitos vínculos de amizade com mulheres negras e de não compreender que a luta por igualdade de mulheres negras é, também, em seu favor, visto que a superexploração e a opressão de mulheres negras tende ao rebaixamento de todas as mulheres. Muitos progressistas, e, até mesmo, alguns comunistas, são ainda culpados de explorar trabalhadoras domésticas negras, recusando contratá-las através do sindicato de empregadas domésticas (ou recusando auxílio à expansão dos sindicatos para locais onde ainda não existe), e, em geral, participando da difamação de "empregada" quando em conversas com seus vizinhos burgueses e suas próprias famílias. Então, existe a "preocupação" de que a trabalhadora doméstica explorada não "fala", ou não é "amigável", com seu empregador, ou o hábito de assumir que é dever do empregador progressista branco "informar" à mulher negra sobre a exploração e opressão que ela, sem dúvida, conhece muito intimamente.

A persistente contestação de cada comentário chauvinista no que diz respeito à mulher negra é vitalmente necessária, se quisermos romper a compreensível desconfiança por parte de mulheres negras, afastadas pelo chauvinismo branco com que elas se deparam em círculos progressistas.

\section{Manifestações do chauvinismo branco}

Algumas das mais grosseiras expressões de chauvinismo podem ser encontradas em eventos sociais, onde, muito frequentemente, homens e mulheres brancos e homens negros dançam, enquanto mulheres negras são preteridas. A aceitação dos padrões da 
classe dominante branca da "atratividade" feminina (tal como pele clara), a incapacidade de tratar com polidez mulheres negras e de integrar mulheres negras em posições de liderança em organizações são outras formas de chauvinismo.

Outro violento aspecto da opressão do Jim Crow contra a mulher negra é expresso nas numerosas leis direcionadas a ela quanto a direitos de propriedade, casamentos inter-raciais (originalmente projetada para prevenir homens brancos no sul [dos Estados Unidos] de casarem com mulheres negras) - a leis que impedem e proíbem o direito de escolha, não somente de mulheres negras, mas, também, de homens brancos e negros e mulheres brancas.

Para mulheres e homens progressistas brancos, especialmente para os comunistas, manter relações com homens e mulheres negros é, acima de tudo, uma questão de adesão estrita à igualdade social. Isso significa nos livrar da posição em que, às vezes, se encontram certos progressistas e comunistas que lutam contra os problemas econômicos e políticos que afligem o povo negro, mas "definem os limites" quando se trata de relações sociais ou casamento inter-racial. Colocar essa questão como "pessoal", e, não, como uma questão política, quando ela surge, é ser culpado do pior tipo de pensamento social-democrataburguês-liberal em relação à questão negra na vida americana; é como estar impregnado das venenosas teorias branco-chauvinistas de um Bilbo ou um Rankin. ${ }^{10} \mathrm{O}$ mesmo ocorre quando se fala em garantia da "segurança" de crianças, que só irá aumentar por via da luta por libertação e igualdade de todas as nações e povos, e não blindando crianças de conhecer essa luta. Isso significa que devemos nos livrar de atitudes burguesas liberais que "permitem" filhos negros e brancos de pais progressistas brincarem juntos em acampamentos quando jovens, mas colocam um limite quando as crianças chegam à adolescência $e$ passam a estabelecer relações amorosas.

Não há dúvida de que os ideólogos burgueses têm tido sucesso em desenvolver uma ofensiva ideológica especial destinada à degradação da mulher negra. Essa degradação é parte integrante da propagada ofensiva ideológica e reacionária contra mulheres [que teriam como única função social] "a cozinha, a igreja e crianças". Entretanto, eles não podem falar da casa como o "lugar" da mulher negra, sem o prejuízo de sua credibilidade; o lugar das mulheres negras tem sido as cozinhas de outras pessoas. Por isso, a tarefa desses ideólogos tem sido intensificar teorias da "superioridade" masculina em relação à mulher negra, desenvolvendo testes de laboratórios, que denominam "atitudes introspectivas", seguindo a nova escola da "psicologia da inferioridade" da mulher. O real propósito de uma profusão de artigos, livros etc. é obscurecer a verdadeira responsabilidade pela opressão da mulher negra, espalhando a pífia noção burguesa sobre uma "guerra dos sexos" e "ignorando" a luta de mulheres e homens negros - de todo o povo negro contra seu opressor comum, a classe dominante branca.

Expressões chauvinistas também incluem o espanto paternalista quando se descobre que negros têm profissões. Mulheres negras com profissões são confrontadas frequentemente com observações do tipo: "Sua família deve estar muito orgulhosa de você, não é?". Nessa altura, há a prática inversa de perguntar a mulheres negras profissionais se "há alguém em sua família" que gostaria de aceitar um emprego como trabalhadora doméstica.

A responsabilidade de superar essas formas especiais de chauvinismo branco repousa, não com a "subjetividade" da mulher negra, como muitas vezes é colocado, mas, diretamente, nos ombros de homens e mulheres brancas. Homens negros têm uma responsabilidade

\footnotetext{
${ }^{10}$ Nota da tradutora: Theodore Gilmore Bilbo (1877-1947) foi um político americano, filiado ao partido democrata, membro da Klu Klux Klan e defensor da segregação racial. John Elliott Rankin (1882-1960), também membro do partido democrata, defendia políticas segregacionistas e com base na supremacia branca.
} 
especial, particularmente em extirpar atitudes de superioridade masculina em relação a mulheres em geral. Existe a necessidade de extirpar atitudes "assistencialistas" e paternalistas voltadas a mulheres negras. Em certa comunidade, uma líder sindicalista negra, a tesoureira do seu partido, ouvia de uma progressista branca, depois de toda reunião: "Deixe-me ficar com o dinheiro, alguma coisa pode acontecer com você". Em outro caso, uma trabalhadora doméstica negra que queria se juntar ao Partido [Comunista] ouviu de seu empregador, um comunista, que ela era "muito atrasada" e que "não estava pronta" para ingressar no Partido. Em outra comunidade, que, desde a guerra, tem tido uma população de sessenta por cento de negros para quarenta por cento de brancos, mães brancas progressistas se mobilizaram para retirar seus filhos da escola local. Só após a iniciativa da organizadora da seção local do Partido [Comunista], uma mulher negra, iniciou-se uma luta que forçou a mudança do regime que tinha sido estabelecido pelo diretor da escola, cedendo aos seus próprios preconceitos e das mães [brancas]. Esse regime envolvia uma classe especial em que algumas crianças brancas ficavam separadas em companhia de "crianças negras selecionadas", em o que foi denominado como "classe experimental em relações raciais".

Essas atitudes chauvinistas, particularmente expressas em direção à mulher negra, são indubitavelmente uma importante razão para a grande insuficiência de participação de mulheres negras em organizações progressistas em nosso Partido [Comunista] como membros e como líderes.

A burguesia americana, devemos nos lembrar, está consciente do presente papel e do grande potencial da massa de mulheres negra e, portanto, não se opõe a "jogar migalhas" para negros que traem seu povo e seguem o comando do imperialismo.

Em face da exposição de sua insensibilidade para com mulheres negras; em face dos crescentes protestos contra linchamentos não punidos e linchamentos legais "ao estilo nortista", Wall Street está concedendo algumas posições simbólicas para mulheres negras. Assim, Anna Arnold Hedgeman, que desempenhou um papel central no Comitê Nacional Negro do Partido Democrata para eleger Truman, foi recompensada com a indicação como assistente de [Oscar] Ewing, Administrador da Agência Nacional de Segurança. Da mesma forma, o Governador Dewey indicou Irene Diggs ${ }^{11}$ para um alto posto administrativo do governo do estado de Nova lorque.

Outro indício que aponta para tentativas de restringir a militância de mulheres negras foi o convite do Departamento de Estado para uma representante do Conselho Nacional de Mulheres Negras - a única organização negra convocada - para presenciar a assinatura do Tratado do Atlântico Norte.

\section{Questões centrais da luta}

Existem muitas questões centrais enfrentadas por mulheres negras, em torno das quais lutas devem ser travadas. Mas, nenhuma [luta] dramatiza tanto a situação de opressão feminina do que o caso de Rosa Lee Ingram, mulher negra, viúva e mãe de 14 crianças duas das quais estão mortas - que enfrenta prisão perpétua em uma prisão na Geórgia pelo "crime" de se defender de avanços indecentes de um "supremacista branco". O caso de Ingram ilustra a indigência, a opressão da família negra na América. Isso ilumina, particularmente, a degradação da mulher negra - atualmente - sob a democracia burguesa americana em direção ao fascismo e à guerra. Isso reflete os insultos diários a que mulheres negras estão submetidas em lugares públicos, não importa qual sua classe social, status ou posição. Isso expõe o álibi hipócrita dos linchadores de homens negros que,

${ }^{11}$ Nota da tradutora: Antropóloga negra norte-americana Dra. Ellen Irene Diggs (1906-1998) foi mais bem conhecida por sua pesquisa sobre a cultura e sociedade afro-latina americana e a história da diáspora africana. 
historicamente, vem se escondendo debaixo das saias de mulheres brancas, quando tentam encobrir seus crimes sujos com o "cavalheirismo" de "proteger mulheres brancas". Mas, hoje, mulheres brancas são irmãs nos movimentos abolicionista e sufragista, devem se levantar para desafiar essa mentira e todo o sistema de opressão contra o negro.

A história americana é rica em exemplos do custo - para os direitos democráticos de homens e mulheres - da incapacidade em travar essa luta. As sufragistas, durante suas primeiras prisões, eram propositadamente colocadas em celas próximas a prostitutas negras, para humilhá-las. Elas tiveram a sabedoria de entender que a intenção era fazer a experiência tão dolorosa que nenhuma mulher ousaria desafiar e lutar por seus direitos, se elas tivessem que enfrentar tais consequências. Mas essa foi uma lacuna histórica das líderes do movimento sufragista. Predominantemente provenientes da burguesia e da pequena burguesia, elas falharam em relacionar sua própria luta com a luta por completos direitos democráticos para o povo negro, após a emancipação.

Uma consciência em desenvolvimento sobre a questão da mulher atualmente, portanto, não deve deixar de reconhecer que a questão negra nos Estados Unidos é anterior, e não igual, à questão da mulher; apenas na medida em que nós lutemos contra todas expressões e ações do chauvinismo em relação ao povo negro, e lutemos pela completa igualdade do povo negro, as mulheres poderão avançar, como um todo, sua luta por direitos iguais. Para o movimento de mulheres progressistas, a mulher negra, que acumula sua condição de trabalhadora, negra e mulher, é a conexão vital para essa elevação da consciência política. Na medida em que, ulteriormente, a causa da mulher negra trabalhadora for promovida, ela estará autorizada a tomar seu lugar legítimo na liderança do proletariado negro no movimento de libertação nacional, e por sua ativa participação, contribuir com toda a classe trabalhadora americana, da qual a histórica missão é a conquista de uma América Socialista - a garantia final e completa da emancipação feminina.

A luta pela liberdade de Rosa Lee Ingram é um desafio para todas as mulheres brancas e todas as forças progressistas, que devem começar a se perguntar: por quanto tempo iremos permitir que esse crime covarde contra todas as mulheres, contra o povo negro, fique impune? A condição de Rosa Lee Ingram e de suas irmãs também traz consigo um desafio para trabalhadores da cultura progressista escreverem e cantarem sobre a mulher negra em sua coragem e dignidade.

No recente estabelecimento do Comitê Nacional pela Libertação da Família, Ingram preenche uma necessidade há muito sentida, desde a inicial mobilização, que forçou a conversão da sentença dada a Senhora Ingram de pena de morte pela de prisão perpétua. Esse Comitê Nacional, encabeçado por Mary Church Terrell, uma das fundadoras da Associação Nacional de Mulheres Negras, inclui, entre suas líderes, algumas mulheres proeminentes, negras e brancas, como Therese Robinson, grandes diretoras nacionais do Comitê pela Liberdade Civil de Elks, Ada B. Jackson, e a Dra. Gene Weltfish.

Um dos primeiros passos do Comitê foi a visita de uma delegação de cidadãos negros e brancos para essa corajosa militante negra e mãe aprisionada em uma cela na Geórgia. A quantidade de apoio foi tão grande, que as autoridades na Geórgia permitiram que a delegação a visitasse sem impedimentos. Desde então, entretanto, em retaliação ao movimento de massa que se formava, agentes do governo transferiram Ingram, que sofre de um problema severo no coração, para uma penitenciária pior, em Reedsville.

Apoiar o trabalho desse comitê se torna uma primeira necessidade para todos os progressistas, particularmente para as mulheres. O Presidente Truman deve ser demovido de seu fingimento de "nada saber" sobre o caso Ingram. Para Libertar os Ingrams, o apoio deve se concentrar no sucesso da campanha de um milhão de assinaturas, e em uma ação na ONU para um pronunciamento, que será peticionado em breve. 
A luta por empregos para a mulher negra é uma questão primordial. A crescente crise econômica, com sua montanha de desempregos, cortes de salários e crescimento de despejos, está tendo impactos mais profundos nas massas negras. Em uma comunidade negra após outra, mulheres negras, as últimas a serem contratadas e as primeiras a serem demitidas, são as que mais sofrem por causa do desemprego. Lutas devem ser travadas para conquistar empregos para mulheres negras na indústria básica, em posições administrativas, nas comunidades e em empresas privadas.

A bem sucedida campanha do Partido Comunista na região leste de Nova lorque, a fim conquistar empregos para mulheres negras nas lojas de variedades, resultou na contratação de mulheres negras em toda a cidade, mesmo em comunidades predominantemente brancas. Essa campanha se entendeu para a Nova Inglaterra e deve ser promovida em outros lugares.

Aproximadamente 15 agências governamentais não contratam negros de modo algum. Essa política dá sanção oficial, e, ao mesmo tempo, incentiva ainda mais a política universal do Jim Crow dos exploradores capitalistas. Uma campanha para conseguir empregos para mulheres negras aqui seria, portanto, um grande avanço para a luta global por empregos para homens e mulheres negros. Além disso, teria um efeito eficaz em expor a hipocrisia do programa de "Direitos Civis" da administração Truman.

Uma luta intensa também terá que ser feita contra a prática crescente do Serviço de Emprego dos Estados Unidos de encaminhar mulheres negras apenas para o serviço doméstico ou de cuidados pessoais, a despeito de suas qualificações para outros trabalhos.

Onde existe percepção do papel especial de mulheres negras, lutas bem-sucedidas podem ser iniciadas, com o apoio de trabalhadores brancos. Um exemplo recente foi a iniciativa tomada por trabalhadores comunistas brancos do setor de vestuário, em uma fábrica que emprega 25 mulheres negras, com três máquinas paradas. A questão da promoção de mulheres negras se tornou vital. Um movimento de boicote foi iniciado e as máquinas permanecem sem uso, até o momento da escrita deste artigo. Os trabalhadores brancos se recusam a aderir ao [critério] de antiguidade estrita às expensas das trabalhadoras negras. Enquanto isso, negociações continuam sobre esse assunto. Semelhantemente, em um sindicato de trabalhadores automobilísticos da empresa Packard, em Detroit, uma luta pela manutenção de mulheres na indústria e pela promoção de 750 mulheres, a grande maioria das quais era negra, foi ganha recentemente.

\section{A luta por paz}

Ganhar a mulher negra para a luta por paz é decisivo para todas as lutas. Ainda durante a guerra contra o Eixo, mulheres negras tiveram que chorar por seus filhos soldados, linchados enquanto serviam em um exército sob o Jim Crow. Em vista disso, elas estariam desinteressadas de uma luta por paz?

Os esforços dos bipartidários fabricantes de guerras em ganhar o suporte de organizações de mulheres em geral têm influenciado muitas organizações de mulheres negras, que, em suas convenções no último ano, adotaram plataformas de políticas internacionais favorecendo o Plano Marshall e a Doutrina Truman. Muitas dessas organizações trabalharam com grupos que têm posições abertamente anti-imperialistas.

É evidente que há um profundo sentimento por paz entre mulheres negras, que pode ser mobilizado para uma ação efetiva, não somente para a magnífica resposta para as reuniões de Eslanda Goode Robeson, mas, também, na posição anunciada semana passada pela mais antiga organização de mulheres negras, sob a liderança de Christine C. Smith, no sentido de instar uma mobilização nacional da mulher negra americana em 
apoio às Nações Unidas. A esse respeito, será muito proveitoso trazer para nosso país o conhecimento das magníficas lutas de mulheres no norte da África, que, mesmo em falta das necessidades materiais elementares, têm organizado um movimento forte por paz se unindo contra a Terceira Guerra Mundial, com 81 milhões de mulheres em 57 países, na Federação Democrática Internacional de Mulheres.

Nosso partido está baseado em princípios marxistas-leninistas, defendendo firmemente um programa de completa igualdade econômica, política e social para o povo negro e de direitos iguais para as mulheres. Quem melhor do que a mulher negra, a mais explorada e oprimida, pertence ao nosso Partido? Mulheres negras podem e devem dar uma enorme contribuição para o cotidiano e o trabalho do Partido. Concretamente, isso significa que a responsabilidade principal recai sobre os companheiros mulheres e homens brancos. Os companheiros negros homens, entretanto, devem participar nessa tarefa. Mulheres negras comunistas em todos os lugares devem, agora, ocupar seu legítimo lugar na liderança do Partido, em todos os níveis.

A grande capacidade, militância e talentos organizacionais da mulher negra podem ser bem utilizadas por nosso Partido, tornando-se uma poderosa alavanca para trazer para dianteira trabalhadores negros - homens e mulheres - como forças dirigentes do movimento de libertação do povo negro, consolidando a unidade negro e branca na luta contra o imperialismo de Wall Street, e pelo enraizamento do Partido entre os mais explorados e oprimidos setores da classe trabalhadora e seus aliados.

Nas células de nosso Partido, devemos conduzir uma discussão intensa sobre o papel da mulher negra, assim como munir os membros do nosso Partido com informações para um claro entendimento de como empreender as lutas necessárias nos pequenos estabelecimentos comerciais e nas comunidades. Devemos dar fim à prática de que muitas mulheres negras que ingressam em nosso Partido - e que, em suas igrejas, comunidades e grupos de solidariedade, são líderes de massas, com uma inestimável experiência com esse tipo de organização para dar a nosso Partido - repentinamente se encontram tratadas em nossas células não como líderes, mas como pessoas que têm que "dar seus primeiros passos" organizacionalmente. Devemos dar fim a essa incapacidade de criar uma atmosfera em nossas células em que novos membros - nesse caso, mulheres negras - enfrentam o "tratamento silencioso" ou tentativas de "moldá-los" a um padrão. Além das implicações do chauvinismo branco desse tipo de estratégia, essas práticas atrapalham a necessidade fundamental para a compreensão marxista-leninista que nosso Partido dá a todos trabalhadores, e que aumenta o seu entendimento político, que o desdém chauvinista pelos talentos organizacionais de novos membros negros, ou para a necessidade de promovê-los à liderança.

Para conquistar a inteira participação de mulheres negras na coalizão antifascista e anti-imperialista, para trazer sua militância e participação para maiores alturas, em lutas atuais e futuras contra o imperialismo de Wall Street, progressistas devem alcançar consciência política em relação ao status especial de opressão [a que são submetidas].

É essa consciência, acelerada pelas lutas, que irá convencer milhares e milhares que somente o Partido Comunista, como a vanguarda da classe trabalhadora, com perspectiva final do Socialismo, pode alcançar a completa igualdade e condições dignas da estatura da mulher negra - e da inteira população negra -, em uma sociedade socialista, na qual contribuições para a sociedade são medidas não pela origem nacional ou por cor, mas uma sociedade em que homens e mulheres contribuem de acordo com a sua habilidade, e, em última instância, sob o Comunismo, recebem de acordo com as suas necessidades. 
An End to the Neglect of the Problems of the Negro Woman!

Abstract: The article is a Portuguese translation of an essay originally published in 1949 by black intellectual and activist Claudia Jones in Political Affairs magazine. In the essay, Jones outlines the origins and dimensions of Black women's oppression and criticizes the inability of communists to mobilize them. In arguing that black women comprised the superexploited segment of the working class, the author centers their political militancy in the global struggle against of fascism and imperialism.

Keywords: Claudia Jones; Communism; Black Women; Black Feminism

Tradução de Edilza Sotero e Keisha-Khan Y. Perry

[Recebido em 25/01/2017 e aprovado em 23/02/2017]

Edilza Sotero (edilzasotero@yahoo.com.br) é doutora em Sociologia pela USP e realizou pesquisa pós-doutoral no Africana Studies Department da Brown University, com financiamento do CNPq. Está vinculada Universidade Federal da Bahia, Salvador.

Keisha-Khan Y. Perry (keisha-khan_perry@brown.edu) é professora no Africana Studies Department da Brown University em Providence, Rhode Island, Estados Unidos.

1016 Estudos Feministas, Florianópolis, 25(3): 1001-1016, setembro-dezembro/2017 